\title{
Benchmarks
}

emic Press, London.

7.Rothstein, R.J. 1983. One-step gene disruption in yeast. Methods Enzymol. 101:202-211.

8.Sambrook, J., E.F. Fritsch, and T. Maniatis. 1989. Molecular Cloning: A Laboratory Manual. CSH Laboratory Press, Cold Spring Harbor, NY.

9.Stark, M.J. and J.S. Milner. 1989. Cloning and analysis of the Kluyveromyces lactis TRP1 gene: a chromosomal locus flanked by genes encoding inorganic pyrophosphatase and histone H3. Yeast 5:35-50.

10.Wach, A., A. Brachat, C. Rebischung, S. Steiner, K. Pokorni, S. Heesen, and P. Philippsen. 1998. PCR-based gene targeting in Saccharomyces cerevisiae. Methods Microbiol. 26:67-81.

The work was supported by the Portuguese project PRAXIS/2/2.1/BIO/1068/ 95. Address correspondence to Dr. Margarida Casal, Centro de Ciências do Ambiente, Departamento de Biologia, Universidade do Minho, 4710-057 Braga, Portugal. e-mail: mcasal@bio.uminho.pt

Received 7 August 2000; accepted 23 April 2001.

Odília Queirós ${ }^{\mathbf{1}, 2,3}$, Margarida
Casal $^{\mathbf{1}}$, Pedro Moradas-
Ferreira $^{\mathbf{2}}$, and Cecília Leão
${ }^{\mathbf{1}}$ Universidade do Minho
Braga
${ }^{2}$ Universidade do Porto
Porto
${ }^{3}$ ISCSN
Paredes, Portugal

Paredes, Portugal

\section{High-Probability Amplification of Genomic DNA Starting from cDNA}

\author{
BioTechniques 31:268-272 (August 2001)
}

After the cDNA for a protein is cloned and sequenced, there is frequently a need to obtain the corresponding genomic DNA to analyze the gene structure and its regulation. There are several published methods designed to pursue this goal. A genomic library may be screened by either Southern blot hybridization or PCR amplification (1) using primers that are designed on the basis of the sequence of cloned cDNAs. Such primers may also be used to amplify by PCR a DNA fragment from genomic DNA extracted from cells. PCR amplification is a frequently used procedure in such studies because of its sensitivity and efficiency.

However, the interruption of exon sequences by introns could introduce a high rate of failure in PCR amplification. When the only information available is the sequence of a cloned eukaryotic cDNA, then it is difficult to predict the presence or location of introns in the sequence of the respective genomic DNAs. Methods such as inverse PCR (2) and anchor PCR (5) have been used to amplify genomic DNA, but these also suffer from the ambiguities caused by the lack of knowledge about the presence and location of introns in genomic sequences. Increasing the probability of successful amplification of genomic DNA sequences using primers based on cDNA sequences remains a problem.

Here, we describe a strategy based on an analysis of known genomic sequences that revealed a minimum length of exons in 200 genes examined that is longer than $40 \mathrm{bp}$. Therefore, the method of amplification of genomic DNA sequences developed was based on the use of two adjacent forward and two adjacent reverse primers, each 20 $\mathrm{bp}$ in length. The primers were designed on the basis of known cDNA sequences but without the knowledge of the ge-

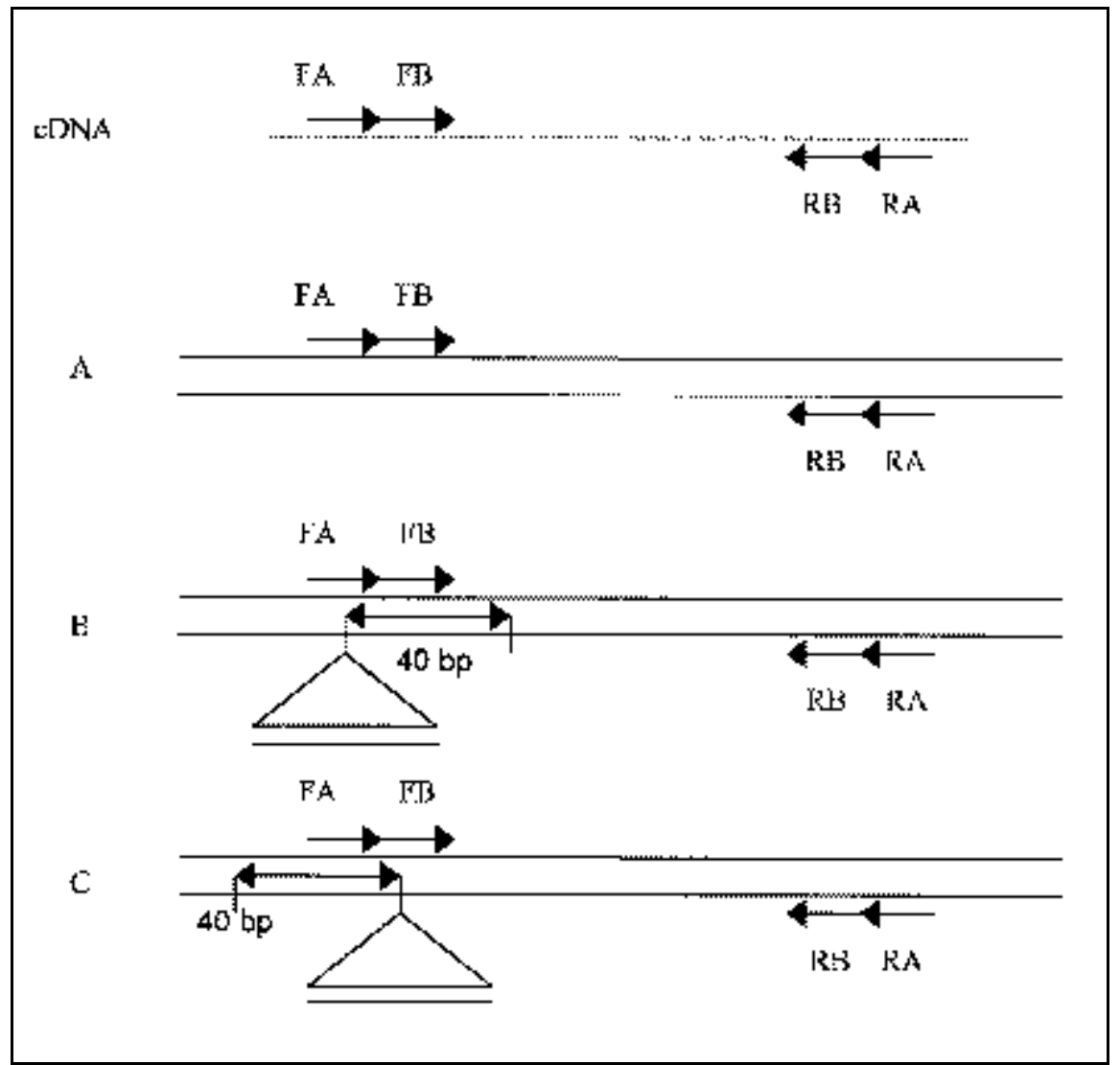

Figure 1. Diagram of the PCR primer design. FA, FB, RA, and RB represent forward $(F)$ and reverse (R) primers. FA and FB are adjacent to each other, as are RA and RB. We assume that the length of all exons is no less than $40 \mathrm{bp}$ and that the genomic DNA between them is in the range of PCR amplification (conventionally less than $5 \mathrm{kbp}$ ). There are three possible outcomes of hybridization of FA and FB to genomic DNA: (A) both FA and FB hybridize to an exon, (B) FA is interrupted by an intron, but FB is not, (C) FB is interrupted by an intron, but FA is not. Thus, there is at least one forward primer that is not interrupted by introns. For the reverse primers, RA and RB, the situation is the same as that for the forward primers. If the combinations of four adjacent primers are used to amplify genomic DNA, then we predict that at least one pair of primers will successfully amplify the genomic DNA sequence between them. 


\section{Benchmarks}

nomic sequences. A theoretical probability of successful PCR amplification of genomic DNA sequences using this approach was calculated to be 1.0 .

To test this model of PCR amplification, we selected the genes for two proteins whose cDNAs were first cloned in our laboratory $(3,4)$ but whose genom ic DNA sequences are unknown. These two proteins are a glutamate-binding protein (GBP) and a glycine-binding (GlyBP) protein subunit of an $N$ methyl-D-aspartate (NMDA) receptor- like complex in neuronal membranes. The primer sequences used were based on the cDNA sequences: forward primer 1, GBPF1 5'-ACCAGGGTATCCCCATGGTC-3'; forward primer 2, GBPF2 5'-CCGGTCCCTATCACAA GGTG-3'; reverse primer 1, GBPR1 5'GAGGCCCTTCCTCCTGGTAG-3'; reverse primer 2, GBPR2 5'-TTCCCA TGCTGAGGTGAGCCAG-3'; forward primer 1, GlyBPF1 5'-TCCGTCTTA CTTGGTGCAGC-3'; forward primer 2, GlyBPF2 5'-CGCTTGAAGACCA
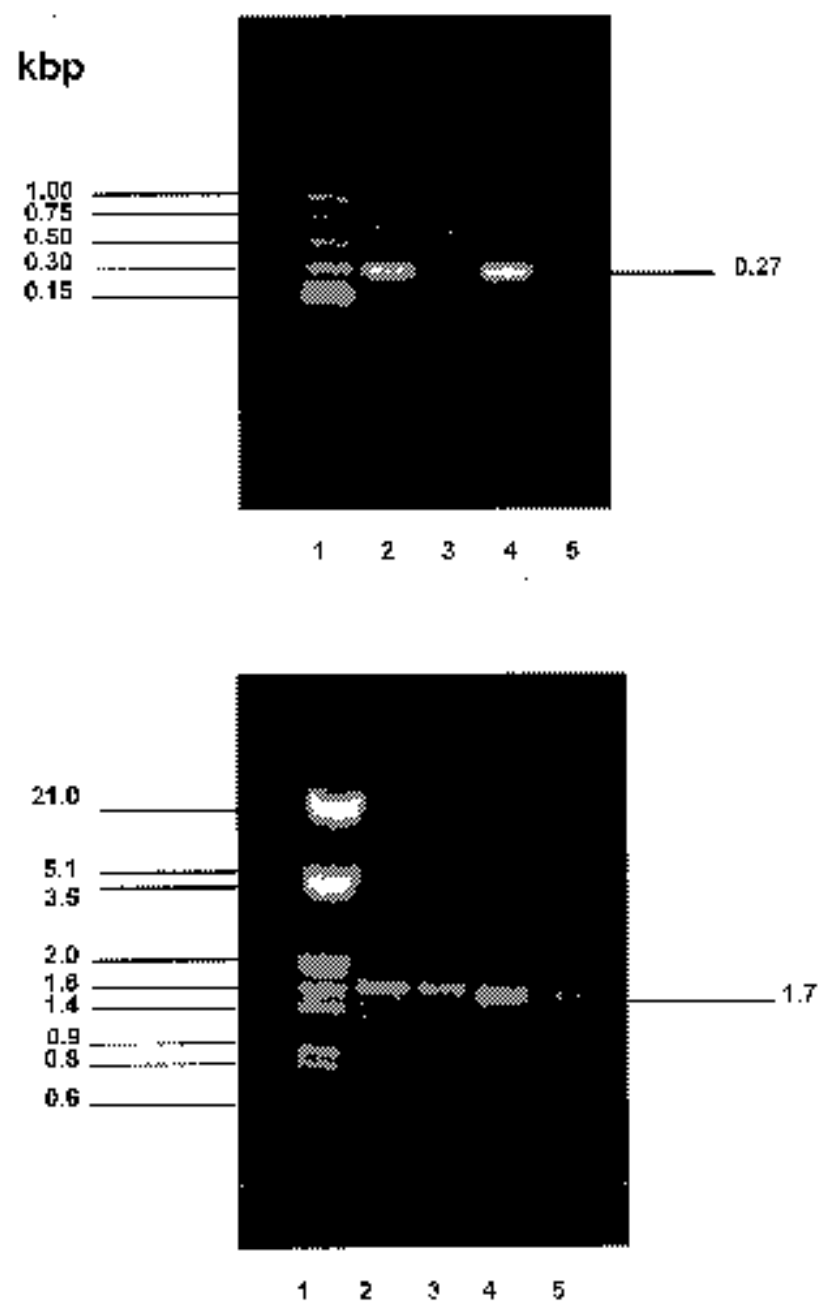

Figure 2. PCR amplification of genomic DNA from liver cells using GBPF1, GBPF2, GBPR1, GBPR2, GlyBPF1, GlyBPF2, GlyBPR1, and GlyBPR2. The upper panel shows PCR amplification results using GBPF1, GBPF2, GBPR1, and GBPR2. Lane 1, PCR markers (Promega); lanes 2-5, DNA amplified from rat genomic DNA using GBPF1 and GBPR1 (lane 2), GBPF1 and GBPR2 (lane 3), GBPF2 and GBPR1 (lane 4), and GBPF2 and GBPR2 (lane 5). Lower panel shows PCR amplification results using GlyBPF1, GlyBPF2, GlyBPR1, and GlyBPR2. Lane $1, \lambda$ DNA markers $(\lambda$ phage DNA digested with HindIII and EcoRI), lanes 2-5, DNA amplified from rat genomic DNA using GlyBPF1 and GlyBPR1 (lane 2), GlyBPF1 and GlyBPR2 (lane 3), GlyBPF2 and GlyBPR1 (lane 4), and GlyBPF2 and GlyBPR2 (lane 5).

ATGCTTCCG-3'; reverse primer 1 , GlyBPR1 5'-CACCTCATATACCTGTCGTC-3'; and reverse primer 2, GlyBPR2 5'-GATTCTGACTGCTGTCTCTCG-3'. All of the primers were synthesized by Integrated DNA Technologies (Coralville, IA, USA).

Genomic DNA was extracted from rat livers. Liver tissue (1-1.3 g) was ground in liquid $\mathrm{N}_{2}$, and the tissue powder was transferred into a $50-\mathrm{mL}$ propylene tube, to which $20 \mathrm{~mL}$ DNA extraction buffer preheated to $45^{\circ} \mathrm{C}$ was added. After the tissue powder had thawed, $40 \mathrm{mg}$ proteinase $\mathrm{K}$ was added, the mixture was incubated at $37^{\circ} \mathrm{C}$ for 4 $\mathrm{h}$, extracted with $20 \mathrm{~mL}$ of $1: 1(\mathrm{v} / \mathrm{v})$ phenol:chloroform mixture, and centrifuged at $10000 \times g$ for $10 \mathrm{~min}$. After three extractions, the supernatant was transferred to a new tube, and RNA was removed by digesting with $40 \mu \mathrm{g}$ RNase at $37^{\circ} \mathrm{C}$ for $30 \mathrm{~min}$. The RNase was removed by extracting the supernatant with $20 \mathrm{~mL}$ of $1: 1$ phenol:chloroform, followed by centrifugation. The DNA in the remaining supernatant fraction was precipitated with $20 \mathrm{~mL}$ isopropanol and pelleted at $10000 \times g$ for $10 \mathrm{~min}$. The DNA pellet was washed with $5 \mathrm{~mL}$ ice-cold ethanol $(70 \% \mathrm{v} / \mathrm{v})$ and air dried at room tem perature. The DNA concentration and purity were determined by the ratio of UV absorbance at 260/280 $\mathrm{nm}$.

Reactions were carried out in a model 2400 temperature cycler (Applied Biosystems, Foster City, CA, USA). The total volume of PCR was 50 $\mu \mathrm{L}$ and contained $70 \mathrm{ng}$ each forward and reverse primer, $2.5 \mathrm{mM} \mathrm{MgCl}_{2}$, $200 \mu \mathrm{M} \mathrm{dGTP}, \mathrm{dCTP}, \mathrm{dATP}$, and dTTp, $100 \mathrm{ng}$ rat genomic DNA, 5 U Taq DNA polymerase, and $\mathrm{Mg}$-free reaction buffer (both from Promega, Madison, WI, USA). The PCR temperature profile was $94^{\circ} \mathrm{C}$ for $1 \mathrm{~min}$, followed by 35 cycles of $94^{\circ} \mathrm{C}$ for $30 \mathrm{~s}, 55^{\circ} \mathrm{C}$ for 1 min, and $72^{\circ} \mathrm{C}$ for $2 \mathrm{~min}$. After the completion of the amplification reactions, the samples were kept at $4^{\circ} \mathrm{C}$. The PCR products were separated by $1 \%$ agarose gel electrophoresis. The amplified DNA fragments were directly sequenced by the ABI PRISM ${ }^{\circledR} 377$ using the dye-terminator sequencing method (Applied Biosystems).

We randomly selected 200 genomic DNA sequences present in GenBank ${ }^{\circledR}$. 
All of the selected genes contained at least three exons. We performed statistical analyses of exon lengths and found that the percentage of exons whose length was less than $40 \mathrm{bp}$ was less than $2 \%$. Based on these calculations, we designed the PCR strategy depicted in Figure 1. According to the results of the statistical analyses, if each primer used in PCR amplification is 20 nucleotides, then two adjacent primers would have a probability equal to 1.0 of hybridizing with an exon sequence. If two adjacent forward and reverse primers are designed as shown in Figure 1 , then there should be at least one pair of PCR primers that could be used to successfully amplify the DNA fragment located between such a pair. In developing this strategy, we made the assumption that all exons in the gene would be no less than $40 \mathrm{bp}$ and that the length of the amplified DNA would be in a range that could be easily amplified by PCR (i.e., no more than $5 \mathrm{~kb}$ for conventional PCR).

The relative probabilities of successful amplifications of genomic sequences using either randomly selected primers or adjacent forward and reverse primers were calculated after certain assumptions were made: $(i)$ the gene is very long, (ii) the PCR method can am plify any length of genomic DNA fragment between two primers as long as the primers match the exon sequences, (iii) all exons in the gene are $40 \mathrm{bp}$ long or longer, and (iv) primers that are not exact complements of genomic DNA sequences will not be elongated by DNA polymerase. These assumptions are not represented in the real world as, for example, sometimes the $5^{\prime}$ end of a primer is interrupted, yet the primer may be elongated by DNA polymerase. The assumptions were made to simplify the calculations. The probability that a 20-bp primer, randomly selected according to the cDNA sequence of the gene, can match an exon in genomic DNA is 0.5 . If every primer selection does not depend on the other primer that has been designed (i.e., the primers are independent), then the probability of expected outcomes for four primers (two forward and two reverse) can be estimated by the method of Bernouilli trials (6). Because the probability of a primer matching or not matching an exon is the same (i.e., 0.5), the probability of a combination of randomly selected primers is $1 / 16$. Therefore, the probability that one pair of four randomly selected primers can amplify a genomic DNA sequence would be 9/16. On the other hand, if two adjacent forward and reverse primers, rather than two pairs of random primers, are used and the same assumptions apply, then the probability of successful amplification of a DNA fragment is 1.0. Under this condition, even if one of the primers of a forward or reverse pair does not match the sequence of genomic DNA, then the other primer would match and the correct PCR amplification would be achieved.

This method would increase the probability of successful amplification of genomic DNA if the assumed conditions apply. We realize, that for various reasons, some primers designed may not work. Nevertheless, as the experimental results indicate, our strategy can systematically increase the probability for successful genomic DNA amplification when there is only knowledge of cDNA sequences.

Pairs of adjacent forward and reverse primers (Figure 1) were designed according to the cDNA sequences of GBP and GlyBP. Using these primers, we successfully amplified the respective genomic DNA fragments from the liver cell DNA of Sprague-Dawley rats (Figure 2). Successful amplification was confirmed by DNA sequencing. Only one of the primers of GBP failed to amplify any DNA fragments (Figure 2, lane 3, upper panel). After we sequenced the genomic DNA of the GBP that was amplified by the other primer combinations, we found that 12 bases of this primer extended into an adjoining intron and, therefore, would not have hybridized with the complementary genomic DNA strand. All primers for GlyBP successfully amplified genomic DNA sequences for GlyBP. They were all located in exons of the GlyBP gene.

The strategy used in these experiments was successful in amplifying DNA fragments from rat genomic DNA for the two target proteins. This supported the idea that the use of two closely aligned forward and two reverse primers increase the probability of genomic DNA amplification to 1.0. Based on the theoretical calculations and successful amplification of two genomic sequences from two different genes of unknown sequence, we believe that this method should lead to high probabilities of successful PCR amplification of genomic sequences. Confirmation of the validity of this approach will require further testing with several other genomic clones.

\section{REFERENCES}

1.Harwood, A.J. 1996. Use of polymerase chain reaction to screen phage libraries, $\mathrm{p}$. 335-339. In A.J. Harwood (Ed.), Basic DNA and RNA Protocols, vol. 58. Humana Press, Totowa, NJ.

2.Innis, M.A., D.H. Gelfand, J.J. Sninsky, and T.J. White. 1989. Amplification of flanking sequences by inverse PCR, p. 219-227. In M.A. Innis, D.H. Gelfand, J.J. Sninsky, T.J. White (Eds.), PCR Protocols, A Guide to Methods and Applications. Academic Press, San Diego.

3.Kumar, K.N., K.K. Babcock, P.S. Johnson, X. Chen, M. Ahmad, and E.K. Michaelis. 1995. Cloning of the cDNA for a brain glycine-, glutamate- and thienylcyclohexylpiperidine-binding protein. Biochem. Biophys. Res. Commun. 216:390-398.

4.Kumar, K.N., N. Tilakaratne, P.S. Johnson, A.E. Allen, and E.K. Michaelis. 1991. Cloning of cDNA for the glutamate-binding subunit of an NMDA receptor complex. Nature 354:70-73.

5.Loh, E.Y., J.F. Elliot, S. Cwirla, L.L. Lanier, and M.M. Davis. 1989. Polymerase chain reaction with single-sided specificity: analysis of T cell receptor $\delta$ chain. Science 243:217220.

6.Pitman, J. 1992. Probability, p. 27-288. Springer-Verlag, New York.

This work was supported by the National Institutes of Health grant nos. AAO4732, AA11419, and AG12993 to E.K.M. Address correspondence to Dr. Elias K. Michaelis, 5064 Malott Hall, Department of Pharmacology and Toxicology, University of Kansas, Lawrence, KS 66044, USA. e-mail: emichaelis@ukans.edu

Received 13 February 2000; accepted 1 May 2001.

Dongwei Hui, Xiaodong Bao, and Elias K. Michaelis University of Kansas Lawrence, KS, USA

For reprints of this or any other article, contact Reprints@BioTechniques.com 